Иванова Н.А. ${ }^{1}$, Бурденный А.М. ${ }^{1,2}$, Логинов В.И. ${ }^{1,3}$, Кураева Т.Л. ${ }^{4}$, Носиков В.В. ${ }^{2}$ Роль полиморфных маркеров гена IL10 в патогенезе сахарного диабета 1-го типа

\author{
'ФГБНУ «Научно-исследовательский институт общей патологии и патофизиологии», \\ 125315, г. Москва, Россия, ул. Балтийская, д. 8; \\ 2ФГБУН «Институт биохимической физики имени Н.М. Эмануэля» РАН, \\ 119334, г. Москва, Россия, ул. Косыгина, д. 4; \\ ${ }^{3}$ ФГБНУ «Медико-генетический научный центр имени акад. Н.П. Бочкова», \\ 115478, г. Москва, Россия, ул. Москворечье, д. 1; \\ ${ }^{4}$ ФГБУ «НМИЦ эндокринологии» Минздрава России, \\ 117036, г. Москва, ул. Дм. Ульянова, д. 11
}

Сахарный диабет типа 1 (СД1) представляет собой многофакторное заболевание, которое характеризуется аутоиммунной природой. Важным фактором в патогенезе СД1 является генетическая предрасположенность, характеризующаяся наличием функциональных однонуклеотидных замен (SNP) в генах цитокинов, ответственных за воспаление. Предполагают, что длительное хроническое воспаление приводит к необратимому разрушению $\beta$-клеток поджелудочной железы и может быть объяснено наличием функциональных полиморфных маркеров в генах-антагонистах.

Цель исследования - изучение частоты аллельных вариантов ряда полиморфных маркеров гена IL 10 при CД1 у жителей Москвы и Московской области.

Методика. В работу включено 366 больных СД 1 типа и 526 здоровых индивидов русского происхождения. Группу больных составили пациенты с наличием сахарного диабета 1 типа различной манифестации с общей медианой $41 \pm 5$ лет. Обе группы выравнены по полу и возрасту. Определение генотипов полиморфных маркеров rs 1800896, rs 1800872 и rs3024505 гена IL10 проводилось с помощью ПЦР «в реальном времени» на амплификаторе «Real-time CFX96 Touch» (Bio-Rad, CШA) c использованием готовой смеси для ПЦР qPCRmix-HS (Евроген, Россия) и уникальных праймеров и зондов.

Результаты. В результате проведенного исследования выявлена статистически значимая ассоциация полиморфного маркера rs 1800896 гена IL 10 с повышенным риском развития CД1 ( $\left.\chi^{2}=15.52, O R=1.48, \mathrm{Cl}_{95 \%}=1.23-1.79, p=0,0004\right)$.

Заключение. Полученные результаты дополняют информацию о механизмах возникновения СД типа 1. Внедрение в практику анализа полиморфных вариантов гена IL 10 позволит выявить предрасположенность к развитию этого заболевания, его прогрессированию у пациентов с аутоиммунными заболеваниями и у лиц, находящихся в группе риска.

Ключевые слова: сахарный диабет 1 типа; цитокины; ген IL 10; полиморфизм.

Для цитирования: Иванова Н.А., Бурденный А.М., Логинов В.И., Кураева Т.Л., Носиков В.В. Роль полиморфных маркеров гена IL 10 в патогенезе сахарного диабета 1 типа. Патологическая физиология и экспериментальная терапия. 2020; 64 (3): 29-33.

DOI: $10.25557 / 0031-2991.2020 .03 .29-33$

Для корреспонденции: Бурденный Алексей Михайлович, e-mail: burdennyy@gmail.com

Участие авторов: дизайн эксперимента - Носиков В.В.; получение и анализ результатов - Иванова Н.А., Бурденный А.М.; сбор образцов - Кураева Т.Л.; концепция и дизайн статьи - Бурденный А.М., Иванова Н.А.;

написание и редактирование статьи - Бурденный А.М., Логинов В.И., Носиков В.В., Иванова Н.А. Утверждение окончательного варианта статьи - все авторы.

Финансирование. Исследование не имело спонсорской поддержки.

Конфликт интересов. Авторы заявляют об отсутствии конфликта интересов.

Поступила 15.03.2020

Принята к печати 24.06.2020

Опубликована 21.08.2020

Ivanova N.A. ${ }^{1}$, Burdennyy A.M. ${ }^{1,2}$, Loginov V.I. ${ }^{1,3}$, Kuraeva T.L. ${ }^{4}$, Nosikov V.V. ${ }^{2}$

\title{
The pathogenic role of $I L 10$ gene polymorhisms in type 1 diabetes mellitus
}

'Institute of General Pathology and Pathophysiology, Baltijskaya Str. 8, Moscow 125315, Russian Federation;

${ }^{2}$ N.M. Emanuel Institute for Biochemical Physics, Russian Academy of Sciences, Kosygina Str. 4, Moscow 119334, Russian Federation;

${ }^{3}$ Academician N.P. Bochkov Research Center of Medical Genetics, Moskvorechje Str. 1, Moscow 115478, Russian Federation;

${ }^{4}$ National Medical Research Center for Endocrinology, Dmitriya Uljyanova Str. 11, Moscow 117036, Russian Federation 
Type 1 diabetes mellitus (T1DM) is a multifactorial disease of an autoimmune origin. An important factor in the pathogenesis of T1DM is genetic predisposition characterized by the presence of functional single-nucleotide polymorphisms (SNPs) in the cytokine genes contributing to inflammation. Long-standing, chronic inflammation is considered to result in irreversible destruction of all pancreatic b-cells and may be due to the presence of functional polymorphic markers in genes of inflammation antagonists, such as the interleukin 10 (IL10) gene.

Aim. The aim of this study was to determine the frequency of allelic variants in a number of IL10 gene polymorphic markers in residents of Moscow and the Moscow Region with T1DM.

Methods. The study includes 366 patients with T1DM with different manifestations and a median duration of $41 \pm 5$ years and 526 healthy individuals. The groups were gender- and age-matched. Genotypes of the rs 1800896, rs 1800872, and rs3024505 polymorphic markers of the IL10 gene were determined with real-time PCR on a Real-Time CFX96 Touch amplifier (Bio-Rad, USA) with a qPCRmix-HS ready-mixed PCR kit (Eurogen, Russia) and unique primers and probes.

Results. The rs 1800896 polymorphic marker of the IL10 gene statistically significantly correlated with increased risk of T1DM $\left(X^{2}=15.52, \mathrm{OR}=1.48, \mathrm{Cl}_{95 \%}=1.23-1.79, p=0.0004\right)$. Conclusion. The study results complement the information about T1DM mechanisms of origin and pathogenesis. Implementation in practice of the methods for analyzing polymorphic variants of the IL10 gene will allow revealing a predisposition to this disease and/or its progression in patients with autoimmune diseases or in people at risk. Keywords: type 1 diabetes mellitus; cytokines; IL10 gene; polymorphism.

For citation: Ivanova N.A., Burdennyy A.M., Loginov V.I., Kuraeva T.L., Nosikov V.V. The pathogenic role of IL10 gene polymorhisms in type 1 diabetes mellitus. Patologicheskaya Fiziologiya i Eksperimental'naya Terapiya. (Pathological physiology and experimental therapy, Russian Journal). 2020; 64 (3):29-33. (In Russian).

DOI: 10.25557/0031-2991.2020.03.29-33

For correspondence: Burdennyy Alexey Mihailovitch, Ph.d., I.s.s. of Pathogenomics and Transcriptomics laboratory of Institute of General Pathology and Pathophysiology, e-mail: burdennyy@gmail.com

Contribution: experiment design - Nosikov V.V.; obtaining and analysis of results - Ivanova N.A., Burdennyy A.M.; sample collection -

Kuraeva T.L.; article concept and design - Burdennyy A.M., Ivanova N.A.; writing and editing an article - Burdennyy A.M., Loginov V.I., Nosikov V.V., Ivanova N.A. Approval of the final version of the article - all co-authors.

Acknowledgment. The study had no sponsorship.

Conflict of interest. The authors declare no conflict of interest.

Information about the authors:

Burdennyy A.M., https://orcid.org/0000-0002-9398-8075

Loginov V.I., https://orcid.org/0000-0003-2668-8096

Received 15.03.2020

Accepted 24.06.2020

Published 10.08.2020

\section{Введение}

В настоящее время в клинической медицине благодаря современным молекулярно-биологическим методам исследования, наблюдается значительный прогресс в понимании патогенеза многофакторных заболеваний, в том числе и сахарного диабета типа 1 (СД1). Основной причиной возникновения СД1 является органоспецифическое аутоиммунное разрушение продуцирующих инсулин $\beta$-клеток островков Лангерганса поджелудочной железы [1]. Центральная роль при этом отводится провоспалительным цитокинам. В ряде работ показано, что провоспалительные цитокины, в том числе и интерлейкин 1 (IL1), цитотоксичны для $\beta$-клеток, они участвуют в развитии эндотелиальной дисфункции, IL1 в организме запускает локальную воспалительную реакцию в ткани поджелудочной железы, а также каскад продукции других цитокинов, что в конечном счёте приводит к активации Т- и В-лимфоцитов. «Хроническая» секреция IL1 приводит к модификации T-хелперов, которые в свою очередь активируют цито-

токсические Т-лимфоциты, воздействие которых приводит к необратимому разрушению $\beta$-клеток поджелудочной железы [2-5]. Прямым антагонистом IL1 с противовоспалительными свойствами и со способностью ингибировать производство воспалительных цитокинов и хемокинов является IL10, кодируемый одноимённым геном. Данный белок действует на адаптивный и врожденный иммунитет, подавляет IL1, что существенно снижает производство Т-клеток. При этом должны увеличиваться выживание и пролиферация $\beta$-клеток поджелудочной железы [6].

В настоящее время опубликовано ряд работ, свидетельствующих о влиянии полиморфных маркеров генов, кодирующих противовоспалительные цитокины, в том числе и IL10, на риск развития СД1 [7]. Следует отметить, что в гене IL10 таких функциональных полиморфных маркеров, влияющих на экспрессию гена, найдено около 10, в том числе наиболее значимые: G(-592)T - rs 1800872, T(-1082)C - rs 1800896 и G(10936) 
DOI: 10.25557/0031-2991.2020.03.29-33

А - rs3024505 [8, 9]. Также имеются данные о снижении количества и функциональной активности IL10 y больных с аутоимунными заболеваниями, являющихся носителями аллеля Т полиморфного маркера rs 1800872, расположенного в промоторной области гена [10].

Полиморфный маркер rs3024505 в отличие от двух других маркеров, расположен в 3'-нетранслируемой области (3’UTR) гена IL10, и было высказано предположение, что он также может влиять на уровень экспрессии IL10 [11]. В последующих исследованиях, связанных с изучением хронических воспалительных заболеваний, была показана ассоциация $r s 3024505$ c синдромом Шегрена [12], болезнью Крона [13] и язвенным колитом [14]. Тем не менее вклад этих маркеров в риск развития СД типа 1 остается невыясненным.

Цель исследования - изучение частоты аллельных вариантов ряда полиморфных маркеров гена IL10 при СД типа 1 у жителей Москвы и Московской области.

\section{Методика}

Исследование проводилось с соблюдением принципов добровольности и конфиденциальности в соответствии с «Основами законодательства РФ об охране здоровья граждан» (Указ Президента РФ от 24.12.93 № 2288). Работа выполнена на образцах крови жителей Москвы и Московской области. Протокол исследования одобрен этическим комитетом института.

В настоящую работу включено 2 группы лиц, выравненных по полу и возрасту. Группа больных включала 366 лиц русского происхождения (возраст $41 \pm 5$ лет) с верфицированным сахарным диабетом 1-го типа с различной манифестацией. Контрольная группа включала 526 здоровых индивидов, (пациенты ФГБУ «НМИЦ эндокринологии» Минздрава России, Москва). Выборки были этнически однородны и составлены из рус- ских (на основании паспортных данных), не являющихся родственниками.

Для исследования ассоциации полиморфных маркеров гена IL10 использовали ДНК, выделенную из лейкоцитов венозной крови стандартным методом с использованием фенол-хлороформной очистки. Определение генотипов полиморфных маркеров гена IL10 проводилось с помощью ПЦР «в реальном времени» на амплификаторе «Real-time CFX96 Touch» (Bio-Rad, США) в 25 мкл реакционной смеси с использованием готовой смеси для ПЦР qPCRmix-HS (Евроген, Россия) и уникальных праймеров и зондов (табл. 1). Обозначения полиморфных маркеров даны в соответствии с базой данных dbSNP [15].

Используемые в зондах флуоресцентные красители - FAM (карбоксифлуоресцеин) и НЕX(VIC) (гексахлорофлуоресцеин), тушитель флуоресценции - BHQ-1.

Статистическую обработку результатов проводили с использованием закона генетического равновесия Харди-Вайнберга для аутосомных признаков. Вся статистическая обработка результатов проводилась с помощью калькулятора для расчёта статистики, написанного в программе excel, в соответствии с формулами, предлагаемыми для расчета статистики согласно выбранному критерию. При сравнении частот встречаемости генотипов применяли критерий Пирсона. Комплексную оценку взаимосвязей между исследуемыми генотипами и риском заболевания проводили с помощью логистической регрессии, определяя отношение шансов (OR) и 95\% доверительный интервал $\left(\mathrm{CI}_{95 \%}\right)$, при значении $p \leqslant 0,05$.

\section{Результаты и обсуждение}

В работе исследовано 3 полиморфных маркера rs 1800872 , rs 1800896 и rs3024505 гена IL10 с риском развития СД типа 1. Результаты распределения частот ал-

Праймеры и зонды

\begin{tabular}{|c|c|c|}
\hline "Локус & Праймеры/зонды & "Температура отжига \\
\hline \multirow{3}{*}{$r s 1800872^{*}$} & F: ACAAATCCAAGACAACACTACTAAG & \multirow{3}{*}{$60^{\circ}$} \\
\hline & R: ATGAATACCCAAGACTTCTCCTTGCTA & \\
\hline & VIC/FAM: CCTACAG[G/T]ACAGGCG & \\
\hline \multirow{3}{*}{ rs $1800896^{*}$} & F: ACAAATCCAAGACAACACTACTAAG & \multirow{3}{*}{$60^{\circ}$} \\
\hline & R: ATGAATACCCAAGACTTCTCCTTGCTA & \\
\hline & VIC/FAM: CTTCCCC[T/C]TCCCAAAG & \\
\hline rs $3024505^{* *}$ & VIC/FAM: GTGAGGG[G/A]GACTAGTGTT & $60^{\circ}$ \\
\hline
\end{tabular}

Примечание. *Праймеры и зонды взяты из: [16]. **Праймеры и зонды взяты из: [17]. 
Распределение частот исследованных полиморфных маркеров гена IL10

\begin{tabular}{|c|c|c|c|c|c|c|}
\hline \multicolumn{7}{|c|}{ rs1800872 } \\
\hline \multirow{2}{*}{ Аллель и генотип } & \multicolumn{2}{|c|}{ Частота } & \multirow{2}{*}{$\chi^{2}$} & \multirow{2}{*}{$p$} & \multicolumn{2}{|c|}{ OR } \\
\hline & случай & контроль & & & знач. & $\mathrm{CI}_{95 \%}$ \\
\hline Аллель $G$ & 0.779 & 0.816 & \multirow{2}{*}{1.84} & \multirow{2}{*}{0.175} & 0.80 & $0.57-1.11$ \\
\hline Аллель $T$ & 0.222 & 0.184 & & & 1.25 & $0.90-1.75$ \\
\hline$G G$ & 0.618 & 0.674 & \multirow[b]{2}{*}{3.51} & \multirow[b]{2}{*}{0.173} & 0.79 & $0.63-1.00$ \\
\hline$G T$ & 0.321 & 0.284 & & & 1.04 & $0.86-1.27$ \\
\hline \multirow{2}{*}{ Аллель и генотип } & \multicolumn{2}{|c|}{ Частота } & \multirow{2}{*}{$\chi^{2}$} & \multirow{2}{*}{$p$} & \multicolumn{2}{|c|}{ OR } \\
\hline & случай & контроль & & & знач. & $\mathrm{CI}_{95 \%}$ \\
\hline Аллель T & 0.467 & 0.566 & \multirow{2}{*}{8.21} & \multirow{2}{*}{0.004} & 0.67 & $0.52-0.88$ \\
\hline Аллель C & 0.534 & 0.435 & & & 1.48 & $1.13-1.93$ \\
\hline TT & 0.234 & 0.344 & 15.52 & 0.0004 & 0.67 & $0.56-0.81$ \\
\hline \multirow{2}{*}{ Аллель и генотип } & \multicolumn{2}{|c|}{ Частота } & \multirow[b]{2}{*}{$\chi^{2}$} & \multirow[b]{2}{*}{$p$} & \multicolumn{2}{|c|}{ OR } \\
\hline & случай & контроль & & & знач. & $\mathrm{CI}_{95 \%}$ \\
\hline Аллель G & 0.853 & 0.883 & \multirow{2}{*}{1.68} & \multirow{2}{*}{0.195} & 0.77 & $0.52-1.14$ \\
\hline Аллель А & 0.148 & 0.118 & & & 1.30 & $0.88-1.92$ \\
\hline GG & 0.724 & 0.776 & \multirow{3}{*}{3.45} & \multirow{3}{*}{0.179} & 0.77 & $0.59-1.02$ \\
\hline GA & 0.257 & 0.213 & & & 1.08 & $0.89-1.31$ \\
\hline AA & 0.019 & 0.011 & & & 1.30 & $0.98-1.71$ \\
\hline
\end{tabular}

лелей и генотипов этих полиморфных маркеров в контрольной группе и группе больных представлены в табл. 2.

Для полиморфных маркеров rs 1800872 и rs3024505 гена IL10 статистически значимых ассоциаций с риском развития СД типа 1 выявлено не было.

В то же время нами выявлено статистически значимое увеличение частоты предрасполагающего генотипа СС полиморфного маркера $r s 1800896$ гена IL10 в группе больных СД1 по сравнению с контрольной группой $\left(\chi^{2}=15.52, p=0,0004\right)$. Следует подчеркнуть, что по данному полиморфному маркеру в мировой литературе опубликовано крайне мало печатных работ [18, 19]. Данный полиморфный вариант IL10 приводит к снижению синтеза цитокина, что ведет к снижению противовоспалительной активности [20]. Таким образом, наши результаты расширяют представления о роли изученных полиморфных маркеров в патогенезе СД типа 1.

\section{Заключе ние}

Современные способы исследования генома GWAS (Genome-wide association study) [21] позволили выявить множество новых генов, которые могут быть ассоциированы с СД 1 типа, в том числе и IL10. Полученные данные об ассоциации полиморфного маркера rs 1800896 с риском развития СД1 дополняют информацию о механизмах его возникновения. Раскрытие этих механизмов поможет понять основы патофизиологии СД1 и определить группы людей с высоким риском развития СД1 для проведения профилактических мероприятий. Разработка и внедрение в практику методов анализа полиморфных вариантов генов, используемых для диагностики СД типа 1, позволят выявить возможность развития этой болезни и/или её прогрессирование у пациентов с аутоиммунными заболеваниями или у людей, находящихся в группе риска.

\section{Литература \\ (п.п. 1; 3; 4; 6-21 сM. References)}

2. Нелаева А.А., Хасанова Ю.В., Хоботова Е.С. Роль провоспалительных цитокинов в развитии и прогрессировании микро- и макроангиопатий у пациентов с сахарным диабетом 2-го типа. Ангиология и сосудистая хирургия. 2013; 19(3): 9-12.

5. Супрун Э.В., Терещенко С.В. Особенности антиоксидантного эффекта рецепторного антагониста интерлейкина-1 в условиях моделирования сахарного диабета. Университетская наука: взгляд в будущее. Материалы международной научно-практической конференции, посвященной 81-летию Курского государственного медицинского университета и 50-летию фармацевтического факультета. В 3-х томах. 2016: 393-7. 


\section{DOI: 10.25557/0031-2991.2020.03.29-33}

\section{References}

1. DiMeglio L.A., Evans-Molina C., Oram R.A. Type 1 diabetes. Lancet. 2018; 391(10138): 2449-62. doi: 10.1016/S0140-6736(18)31320-5

2. Nelaeva A.A., Khasanova Yu.V., Khobotova E.S. Role of proinflammatory cytokines in the development and progression of micro- and macroangiopathies in patients with type 2 diabetes mellitus. Angiologiya I sosudistaya khirurgiya. 2013; 19(3): 9-13. PMID: 24300485. (in Russian)

3. Urbanovych A.M., Suslyk H.I., Kozlovska Kh.Yu. Content of sP-selectin and Cytokines in Blood of Patients with Type 2 Diabetes Mellitus and Arterial Hypertension Depending on Diabetes Compensation Condition. International Journal of Chemistry. 2016; 8(2): 123-8. DOI: $10.5539 /$ ijc.v8n2p123

4. Chen L., Deng H., Cui H., Fang J., Zuo Z., Deng J. et al. Inflammatory responses and inflammation-associated diseases in organs. Oncotarget. 2017; 9(6): 7204-18. doi: 10.18632/oncotarget.23208

5. Suprun E.V., Tereshhenko S.V. The antioxidant effect features of the interleukin-1 antagonist receptor in diabetes mellitus modeling. The University science: $a$ view into the future. The content of the international scientific-practical conference devoted to the 81st anniversary of the Kursk State Medical University and the 50th anniversary of the Faculty of Pharmacy. In 3 volumes. [Osobennosti antioksidantnogo effekta retseptornogo antagonista interleykina-1 $v$ usloviyakh modelirovaniya sakharnogo diabeta. Universitetskaya nauka: vzglyad v budushchee. Materialy mezhdunarodnoy nauchno-prakticheskoy konferentsii, posvyashchennoy 81-letiyu Kurskogo gosudarstvennogo meditsinskogo universiteta i 50-letiyu farmatsevticheskogo fakul'teta]. Kursk; 2016: 393-7. (in Russian)

6. Akdis M., Aab A., Altunbulakli C., Azkur K., Costa R.A., Crameri R. et. al. Interleukins (from IL-1 to IL-38), interferons, transforming growth factor $\beta$, and TNF- $\alpha$ : Receptors, functions, and roles in diseases. J Allergy Clin Immunol. 2016; 138(4): 984-1010. doi: 10.1016/j.jaci.2016.06.033

7. Blanter M., Sork H., Tuomela S., Flodström-Tullberg M. Genetic and Environmental Interaction in Type 1 Diabetes: a Relationship Between Genetic Risk Alleles and Molecular Traits of Enterovirus Infection? Curr Diab Rep. 2019; 19(9): 82. doi: 10.1007/s11892-019-1192-8

8. Baxter A.G., Jordan M.A. From markers to molecular mechanisms: type 1 diabetes in the post-GWAS era. Rev Diabet Stud. 2012; 9(4): 201-23. doi: 10.1900/RDS.2012.9.201

9. Shu Y., Chen Y., Luo H., Li H., Tang J., Liang Y. et al. The Roles of IL-10 Gene Polymorphisms in Diabetes Mellitus and Their Associated Complications: A Meta-Analysis. Horm Metab Res. 2018; 50(11): 811-5. doi: 10.1055/a-0651-5051

10. Ying B., Shi Y., Pan X., Song X., Huang Z., Niu Q. et al. Association of polymorphisms in the human IL-10 and IL-18 genes with rheumatoid arthritis. Mol. Biol. Rep. 2011; 38(1): 379-85.
11. Doecke J.D., Simms L.A., Zhao Z.Z., Huang N., Hanigan K., Krishnaprasad K. et al. Genetic susceptibility in IBD: overlap between ulcerative colitis and Crohn's disease. Inflamm. Bowel Dis. 2013; 19: 240-5.

12. Colafrancesco S., Ciccacci C., Priori R., Latini A., Picarelli G., Arienzo F. et al. STAT4, TRAF3IP2, IL10, and HCP5 Polymorphisms in Sjögren's Syndrome: Association with Disease Susceptibility and Clinical Aspects. J Immunol Res. 2019; 2019: 7682827. doi: 10.1155/2019/7682827

13. Mijac D., Petrovic I.V., Djuranovic S., Perovic V., Bojic D., Culafic D. et al. The Polymorphism rs3024505 (C/T) Downstream of the IL10 Gene Is Associated with Crohn's Disease in Serbian Patients with Inflammatory Bowel Disease. Tohoku J Exp Med. 2016; 240(1): 15-24. doi: 10.1620/tjem.240.15

14. Andersen V., Ernst A., Christensen J., Østergaard M., Jacobsen B.A., Tjønneland A. et al. The polymorphism rs3024505 proximal to IL-10 is associated with risk of ulcerative colitis and Crohns disease in a Danish case-control study. BMC Med Genet. 2010; 11: e82. doi: 10.1186/1471-2350-11-82

15. http://www.ncbi.nlm.nih.gov/snp/, Build 153, Released: July 9, 2019.

16. Armingohar Z., Jørgensen J.J., Kristoffersen A.K., Schenck K., Dembic Z. Polymorphisms in the interleukin-10 gene and chronic periodontitis in patients with atherosclerotic and aortic aneurysmal vascular diseases. Journal of Oral Microbiology. 2015; 7:1, 26051. DOI: 10.3402/jom.v7.26051

17. Franke A., Balschun T., Karlsen T.H., Sventoraityte J., Nikolaus S., Mayr G. et al. Sequence variants in IL10, ARPC2 and multiple other loci contribute to ulcerative colitis susceptibility. Nat Genet. 2008; 40(11): 1319-23. doi: 10.1038/ng.221.

18. Mohebbatikaljahi H., Menevse S., Yetkin I., Demirci H. Study of interleukin-10 promoter region polymorphisms $(-1082 \mathrm{~A} / \mathrm{G},-819 \mathrm{~T} / \mathrm{C}$ and $-592 \mathrm{~A} / \mathrm{C})$ in type 1 diabetes mellitus in Turkish population. J Genet. 2009; 88(2): 245-8.

19. Reynier F., Cazalis M.A., Lecoq A., Paye M., Rosa A., Durand A. et al. Lack of association of IL-10 promoter gene variants with type 1 diabetes in a French population. Hum Immunol. 2006; 67(4-5): 311-7.

20. Posadas-Sánchez R., Angeles-Martínez J., Pérez-Hernández N., Rodríguez-Pérez J.M., López-Bautista F., Flores-Dominguez C. et al. The IL-10-1082 (rs1800896) G allele is associated with a decreased risk of developing premature coronary artery disease and some IL10 polymorphisms were associated with clinical and metabolic parameters. The GEA study. Cytokine. 2018; 106: 12-8. doi: 10.1016/j. cyto.2018.02.028

21. Gao P., Uzun Y., He B., Salamati S.E., Coffey J.K.M., Tsalikian E., Tan K. Risk variants disrupting enhancers of TH1 and TREG cells in type 1 diabetes. Proc Natl Acad Sci USA. 2019; 116(15): 7581-90. doi: $10.1073 /$ pnas. 1815336116

\section{Сведения об авторах:}

Иванова Наталья Анатольевна, мл. науч. сотр. лаб. патогеномики и транскриптомики ФГБНУ НИИОПП;

Бурденный Алексей Михайлович, канд. биол. наук, вед. науч. сотр. лаб. патогеномики и транскриптомики ФГБНУ НИИОПП; ФГБУН «Институт биохимической физики им. Н.М. Эмануэля» РАН;

Логинов Виталий Игоревич, канд. биол. наук, вед. науч. сотр. лаб. патогеномики и транскриптомики ФГБНУ НИИОПП; ФГБНУ «Медико-генетический научный центр» РАН;

Кураева Тамара Леонидовна, доктор мед. наук, проф., руководитель отд-ния сахарного диабета детей и подростков ФГБУ «НМИЦ эндокринологии» Минздрава России;

Носиков Валерий Вяиеславович, доктор биол. наук, проф., зав. лаб. постгеномных молекулярно-генетических исследований ФГБУН «Институт биохимической физики им. Н.М. Эмануэля» РАН. 